Supplementary Material for Biochemistry MS\# bi051193b

\title{
AN EXPERIMENT-BASED ALGORITHM FOR PREDICTING THE PARTITIONING OF UNFOLDED PEPTIDES INTO PHOSPHATIDYLCHOLINE BILAYER INTERFACES ${ }^{\dagger}$
}

\author{
Kalina Hristova§ and Stephen H. White ${ }^{\ddagger *}$ \\ ‡Department of Physiology and Biophysics and \\ Program in Macromolecular Structure \\ University of California \\ Irvine, CA 92697-4560 \\ \$Department of Materials Science and Engineering \\ The Johns Hopkins University \\ Baltimore, MD, 21218
}

\begin{abstract}
Keywords: Wimley-White hydrophobicity scales, N-terminal acetylation, C-terminal amidation, prediction of partitioning, peptide design, antimicrobial peptides

Running Title: Terminal-group effects on peptide partitioning
\end{abstract}

*To whom correspondence should be addressed: Univ. of California at Irvine, Dept. of Physiology and Biophysics, Medical Sciences I - D346, Irvine, CA 92697-4560. phone = (949) 824-7122, FAX = (949) 824-8540, and e-mail= 
Wimley and White (1) determined the free energies of transfer $\left(\Delta G_{i f}^{a a}\right)$ from the POPC interface to buffer of whole amino acid residues in unfolded pentapeptides of the form Ac-WL-X-LL-COOH, where $\mathrm{X}$ is any of the twenty natural amino acids. The resulting hydrophobicity scale provides a starting point for a general algorithm for predicting the free energy of transfer any unfolded peptide between the bilayer interface and water. The scale has only limited value, however, in the absence of values for the partitioning of the various $\mathrm{N}$ - and C-terminal groups commonly encountered. The present paper provides useful data on the partitioning of these endgroups.

The data presented describe the energetic consequences of deprotonating or acetylating the N-terminus, and amidation of the C-terminus. Wimley and White (1) determined the free energy cost of protonating the C-terminal carboxyl group. But these are relative changes. Prediction of absolute partitioning free energies requires absolute values for the various endgroups. We describe in this supplement how we determined absolute reference values for the algorithm shown in Figure 7.

We need two absolute reference values, one for an N-terminal group and one for a C-terminal group. Given those reference values, then absolute values for the other endgroups can be computed from the data in Table 2 .

\section{Absolute reference value for $\mathrm{COOH}:-2.2 \mathrm{kcal} \mathrm{mol}^{-1}$}

We estimated the value for partitioning the $\mathrm{COOH}$ group by two methods, using the partitioning free energies $(\Delta G)$ for $\operatorname{AcWL}_{m}(m=1 \ldots 6)$ determined by Wimley and White (1). The general approach for both is based upon the idea of Wimley and White's Figure 1 in which $\Delta \mathrm{G}$ is plotted against $m$. Because the C-terminus is $\mathrm{COOH}$, the $m^{\text {th }}$ is missing a peptide bond. But an additional peptide bond is provided by acetylation of the N-terminus, meaning that the number of peptide bonds $n=m$.

\section{Method 1}

The $\Delta G$ data (bilayer to water) for the $\mathrm{AcWL}_{m}$ peptides with charged carboxy termini ( $\mathrm{pH}$ 8.0) were used (Table 2 of (1)). The hydrophobic free energy contributions of the Trp and Leu sidechains, $\alpha$-carbons, and the acetyl methyl were computed from the accessible surface areas (2) using a solvation parameter of $13.1 \mathrm{cal} \mathrm{mol}^{-1} \AA^{-2}(1)$. These free energies were subtracted from the measured partitioning free energies of 
the $\mathrm{AcWL}_{m}$ peptides. Then cost of protonating the $\mathrm{COO}^{-}$group $\left(2.68 \mathrm{kcal} \mathrm{mol}^{-1}\right)$ was subtracted from each peptide to arrive at values for the partitioning free energies of $(\mathrm{CONH})_{n} \mathrm{COOH}$, which were plotted as a function of $\mathrm{n}$ (Figure S1). The linear fit of the data extrapolates to $-2.23( \pm 0.22) \mathrm{kcal} \mathrm{mol}^{-1}$ for $n=0$, corresponding to the water-tobilayer $\Delta G$ value for the $\mathrm{COOH}$ group. The slope of the line, $1.19( \pm 0.05) \mathrm{kcal} \mathrm{mol}^{-1}$ per residue, is cost $\Delta G_{C O N H}$ of partitioning the peptide bond into the bilayer interface. The published value, derived from the same data in a somewhat different manner is $1.2( \pm 0.1) \mathrm{kcal} \mathrm{mol}^{-1}$ (the larger error results from propagation of experimental errors from original data).

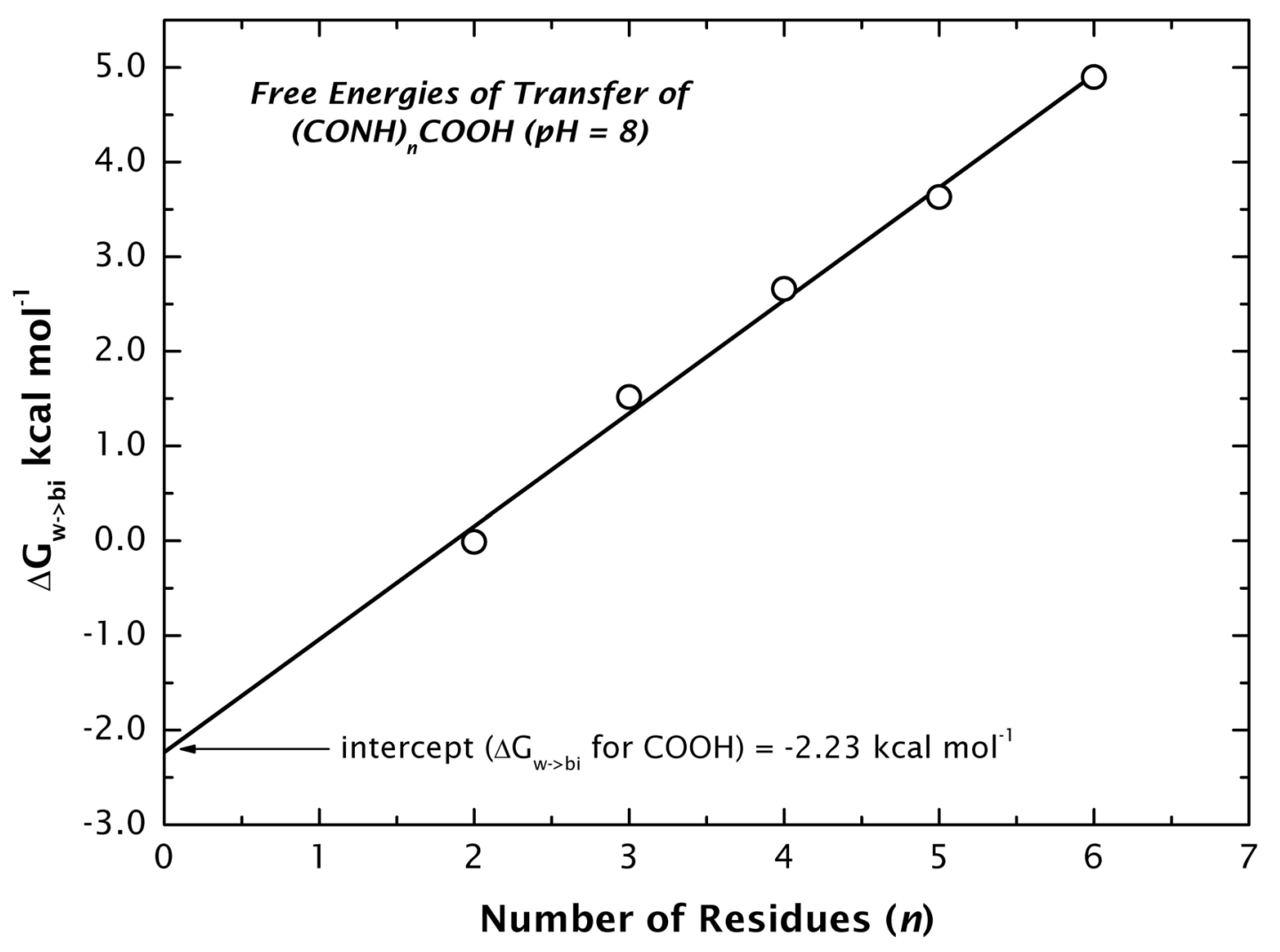

Figure S1

\section{Method 2}

The cost of partitioning Ac- $\mathrm{COO}^{-}$was determined using the same $\mathrm{AcWL}_{m}$ data used in Method 1. In this case, the $\mathrm{AcWL}_{m}$ values were plotted against the number of residues $n=m+1$, and extrapolated to $n=0$ (Figure S2). The extrapolated free energy of partitioning for $n=0$ is $-1.91( \pm 0.19) \mathrm{kcal} \mathrm{mol}^{-1}$. However, this value does not equal 
the $\Delta G$ for Ac-COO- because one of the residues is Trp rather than Leu. The correct value is obtained by subtracting the difference $\Delta G_{\text {if }}^{\text {Trp }}-\Delta G_{\text {if }}^{\text {Leu }}=-1.29 \mathrm{kcal} \mathrm{mol}^{-1}$ (1), which yields $-0.62 \mathrm{kcal} \mathrm{mol}^{-1}$ for $\mathrm{Ac}_{-} \mathrm{COO}^{-}$. The value of $\mathrm{Ac}-\mathrm{COOH}$ is obtained by subtracting the cost of deprotonating the carboxyl group. The $\mathrm{COOH}$ value is obtained from that value by subtracting the methyl group free energy contribution of $-1.11 \mathrm{kcal}$ $\mathrm{mol}^{-1}$, computed from its accessible surface area and the interface solvation parameter (1) $\left(85 \AA^{2} \times 13.1 \mathrm{cal} \mathrm{mol}^{-1} \AA^{-2}\right)$. The final value obtained for $\mathrm{COOH}$ is $-2.19 \mathrm{kcal} \mathrm{mol}^{-1}$, which validates the value obtained by Method 1. We take the transfer free energy of the $\mathrm{COOH}$ group as $-2.2 \mathrm{kcal} \mathrm{mol}^{-1}$.

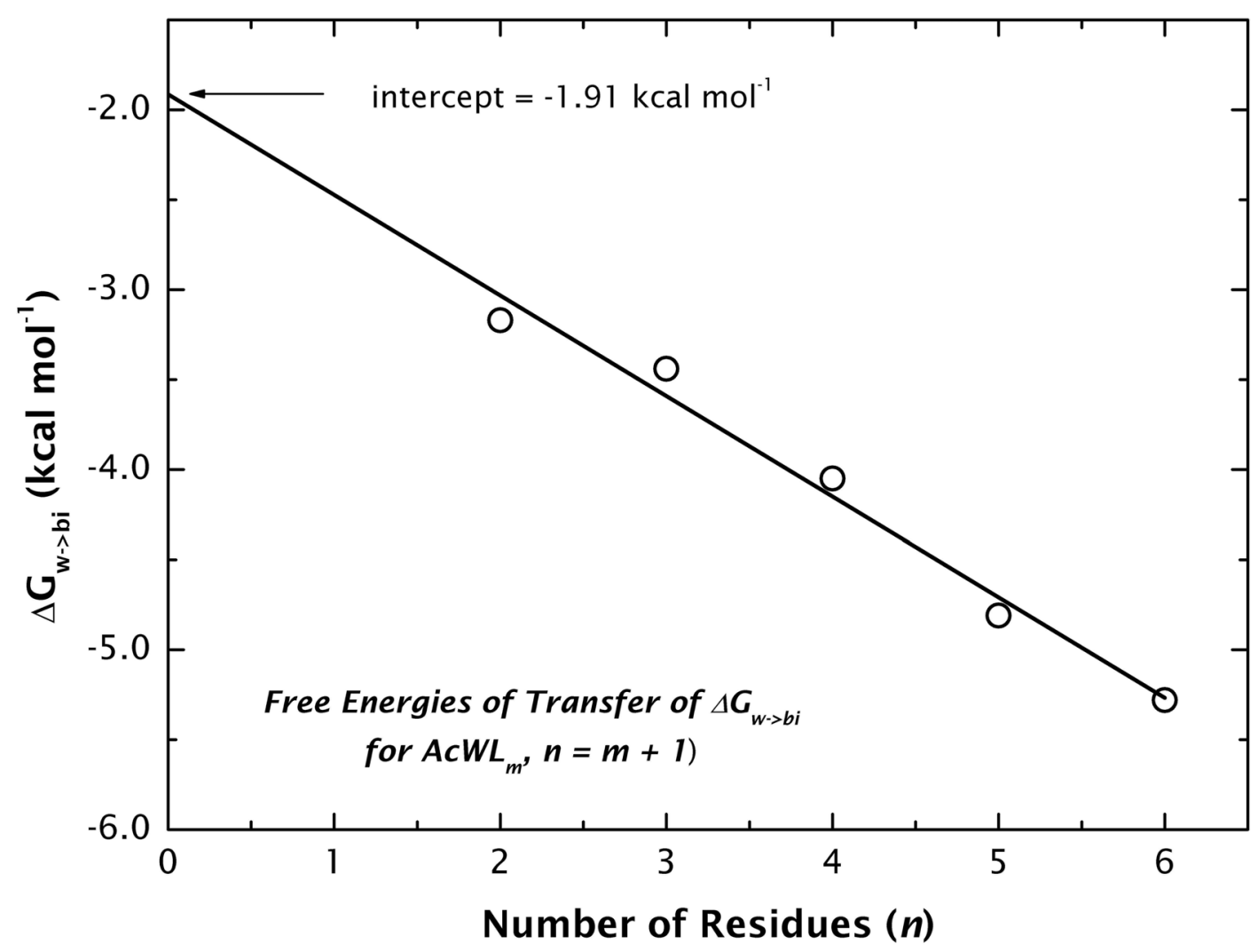

Figure S2

\section{Absolute reference value for $\mathrm{CH}_{3}-\mathrm{CONH}$ (Acetyl group): $0.1 \mathrm{kcal} \mathrm{mol}^{-1}$}

The free energy of transfer into the interface for the methyl group (above) is -1.1 $\mathrm{kcal} \mathrm{mol}^{-1}$, and the free energy of transfer of the peptide bond is $1.2 \mathrm{kcal} \mathrm{mol-1}$. The net value is $+0.1 \mathrm{kcal} \mathrm{mol}^{-1}$. 


\section{References}

1. Wimley, W. C. and White, S. H. (1996) Experimentally determined hydrophobicity scale for proteins at membrane interfaces, Nature Struct. Biol. 3, 842-848.

2. Wimley, W. C., Creamer, T. P., and White, S. H. (1996) Solvation energies of amino acid sidechains and backbone in a family of host-guest pentapeptides, Biochemistry 35, 5109-5124. 